\title{
A piece of broken intubation tube stylet as endobronchial foreign body
}

Tajik Mohammed Shafi, Nithya Haridas, Preeti Belagundi, Asmita A. Mehta

\begin{abstract}
Endotracheal tube stylets are still being used in many medical centres for difficult intubations. In rare cases, it may break inside the trachea during endotracheal intubation and may sometimes move unnoticed deep into the tracheobronchial tree. In this case report, the authors describe a rare complication after endotracheal tube (ETT) stylet intubation in a patient in whom a broken piece of metal guide remained in her tracheobronchial tree. A 69-year-old lady was admitted to our hospital for management of shortness of breath and cough with expectoration. The patient was a known case of chronic obstructive pulmonary disease, cor pulmonale and coronary artery disease. The authors report a case of an unrecognized broken piece of stylet in her tracheobronchial tree and left main bronchus, which was later detected by computed tomography scan and extracted. Despite precise evaluation before use, signs of breakage in the stylet may be missed, and, consequently, it may break inside the trachea and result in serious complications. It is strongly
\end{abstract}

\section{Case summary}

We present a case of a 69-year-old woman who came for the management of chronic obstructive pulmonary disease, cor pulmonale, and coronary artery disease. She presented to us with complaints of shortness of breath with bilateral wheeze and cough with minimal expectoration for 2 weeks. There was also a history of excessive snoring and apneic spells during sleep. There was no complaint of chest pain, hemoptysis, loss of weight or loss of appetite. Her past medical history was significant with recurrent intensive care unit admission requiring mechanical ventilation. She had no other medical comorbidities such as diabetes mellitus, stroke, or seizure disorder.

On examination, she was obese, had a double chin and short neck. There was no pallor, icterus, cyanosis, clubbing, lymph node or oedma. She was conscious oriented, and vitals were stable. Her BMI was $39 \mathrm{~kg} /$ $\mathrm{m}^{2}$. Respiratory system examination revealed wheeze in the bilateral lower axillary region on auscultation. Examination of the other systems was unremarkable. Blood investigations including liver function, renal function tests and serum electrolytes were within normal limits. Arterial blood gas taken on breathing room air showed $\mathrm{pH}: 7.331, \mathrm{PCO}_{2}: 65.1, \mathrm{PaO}_{2}: 50.7$, $\mathrm{HCO}_{3}: 33.9, \mathrm{SO}_{2}: 84 \%$, Lactate: 0.6. The chest radiograph showed a metallic shadow in the trachea extending up to the carina along with calcified trachea. We considered her age behind the reason for tracheobronchial calcification. She was initiated on noninvasive ventilator (NIV) for type two respiratory recommended that the intensivists pay attention to the sounds and movements of the instruments.

Egypt J Bronchol 2019 13:774-777

(C) 2020 Egyptian Journal of Bronchology

Egyptian Journal of Bronchology 2019 13:774-777

Keywords: endotracheal tube, foreign body, obesity, stylet

Department of Pulmonary Medicine, Amrita Institute of Medical Sciences, Amrita Vishwa Vidyappethat, Kochi. Kerala, India

Correspondence to Dr.Asmita Mehta, MD, Clinical Professor, Department of Reaspiratory Medicine, Amrita Institute of Medical Sciences, Amrita Vishwa Vidyapeethem Ponekkara, Kochi, Kerala, 682041, India. Tel: +91484 2801234 (Extn: 5630), Mob: +919037450374, Fax: +91484 2802020; e-mail: asmitamehta@aims.amrita.edu

Received: 11 June 2019 Accepted: 24 November 2019 Published: 21 January 2020

failure along with other supportive medications. Unfortunately, she was not able to tolerate NIV and was refusing for the same. In view of coronary artery disease (CAD) history, a 2D ECHO was taken. It showed good left ventricular function; mild to moderate pulmonary hypertension (PAH); no regional wall motion abnormality; mild tricuspid regurgitation (TR), mitral regurgitation (MR), and sclerotic aortic valve; and grade I diastolic dysfunction. She was suggested to continue colpidogrel, ecosprin, diuretics and other cardiac drugs. As a part of the workup of $\mathrm{PAH}$, a computerized pulmonary angiogram (CTPA) was taken. There was no pulmonary embolism in CTPA, but it showed a radiodense tube extending from the trachea to the left main bronchus (Fig. 1). CTPA findings were suggestive of a foreign body $(\mathrm{FB})$ in the tracheobronchial tree. As no intervention like intubation, endotracheal suctioning or Ryle's tube insertion was performed under our care, we considered it was a suction tube left over during the last admission. She needed bronchoscopic evaluation as a therapeutic/diagnostic intervention. We decided to go ahead with Fiberoptic bronchoscopy. Cardiology fitness was assessed before bronchoscopy, and clopidogrel was stopped 3 days prior. The

This is an open access journal, and articles are distributed under the terms of the Creative Commons Attribution-NonCommercial-ShareAlike 4.0 License, which allows others to remix, tweak, and build upon the work non-commercially, as long as appropriate credit is given and the new creations are licensed under the identical terms. 


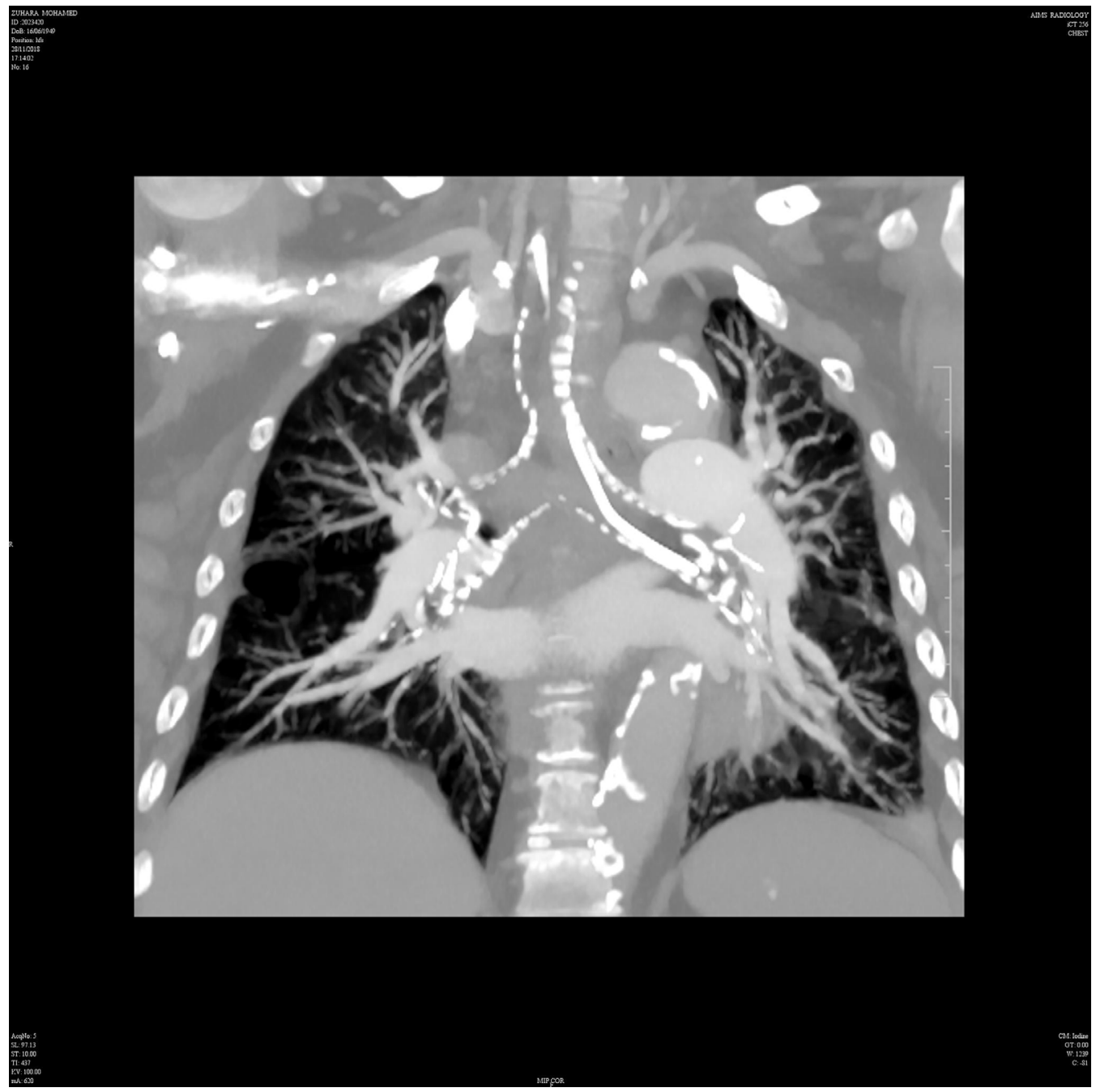

Computed tomography chest showing a radiodense tube extending from the trachea to the left main bronchus.

cardiologist cleared her with no added cardiac risk for the procedure and advised to watch for hypertension during the procedure. Before bronchoscopy, her ABG results were $\mathrm{pH}: 7.363, \mathrm{PCO}_{2}: 55.4, \mathrm{PO}_{2}: 85.1, \mathrm{SO}_{2}$ : $96.2, \mathrm{HCO}_{3}: 30.7$, and Lactate 1 on 11 oxygen via nasal prongs. As she had a history of recurrent ICU admission requiring intubation, we decided to go ahead with fiberoptic bronchoscopic visualization with minimal sedation, and, in case, she could not tolerate it, we planned for endotracheal intubation. She was given $25 \mu \mathrm{g}$ fentanyl along with local anaesthetic $2 \%$ lignocaine. Bronchoscopy revealed a metallic mobile FB in the right main bronchus. It was below $2 \mathrm{~cm}$ of the carina. The lower end of the FB was not seen (Fig. 2). The FB was held with biopsy forceps and brought up to the level of the vocal cords. After that, under direct visualization, the FB was removed with Magill's forceps. The FB was an aluminium rod about $12 \mathrm{~cm}$ in length and $2.5-3 \mathrm{~mm}$ in width (Fig. 3). It looked like an ETT stylet. There was no bleeding after removal. After removal, check bronchoscopy was
Figure 2

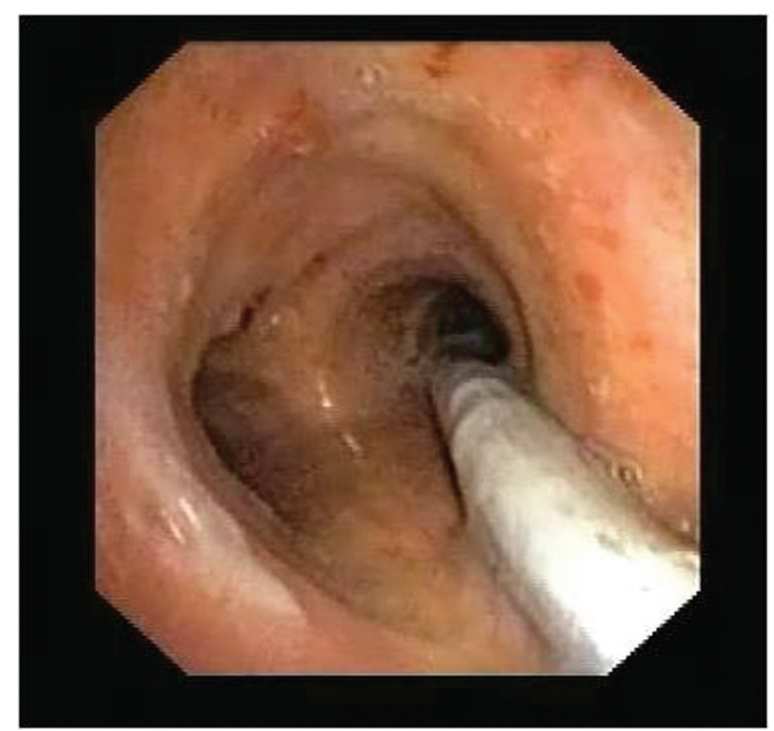

Metallic mobile foreign body seen in the right main bronchus. 


\section{Figure 3}

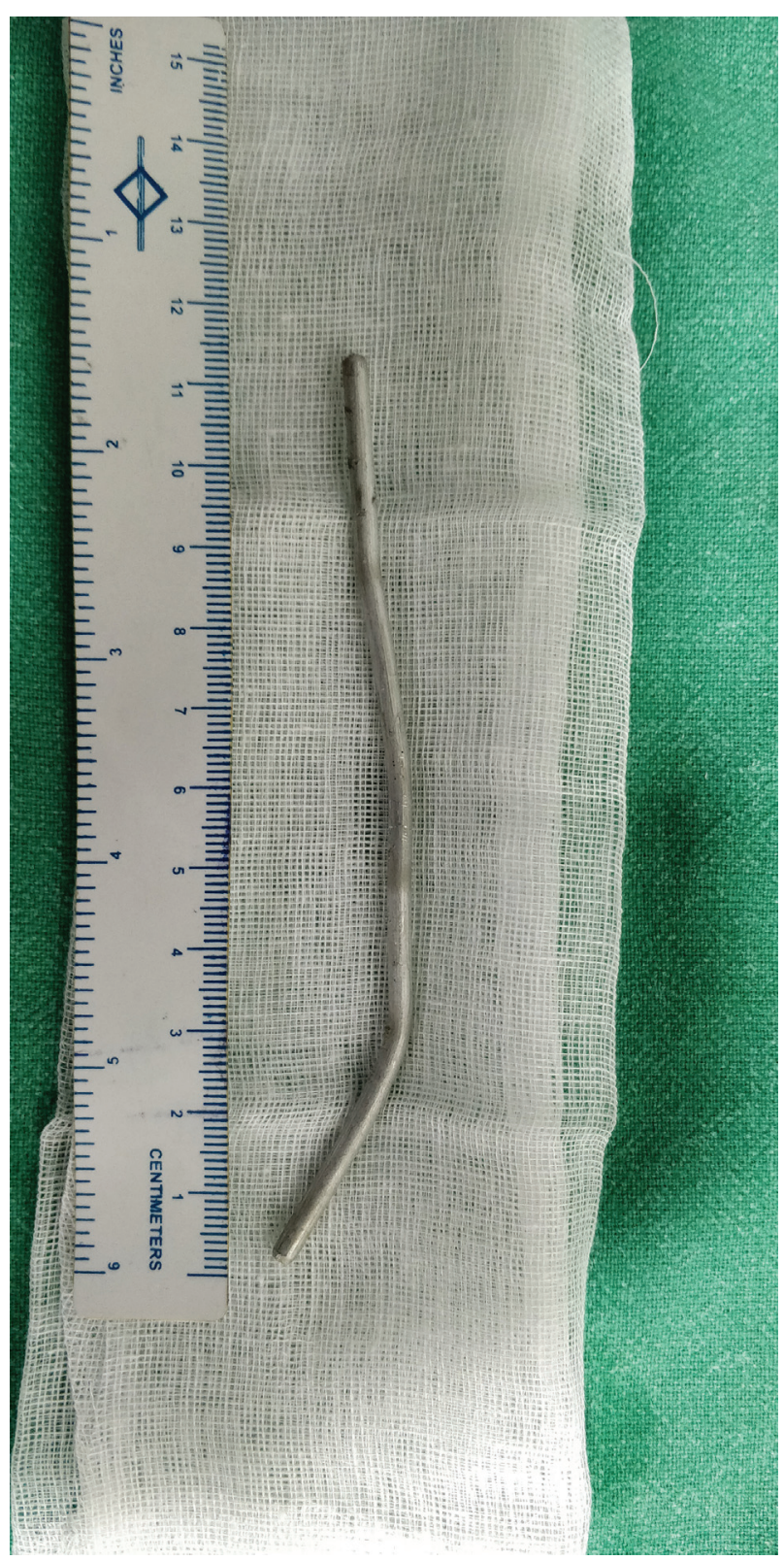

ETT stylet after removal from the airway.

performed, and the airways visualized both the sides up to the subsegmental level were clear. Informed consent from the patient and relative has been obtained prior to writing this case report.

\section{Discussion}

Endotracheal intubation is most of the time a lifesaving procedure. The airways can be managed largely on the basis and preference of an intensivist on the basis of his/her experience and training. However, airway management can be difficult and even seems impossible in some cases even for very experienced people [1]. The endotracheal tube (ETT) stylet is a device that allows the ETT to be stiffened and the shape moulded as desired [2]. Some of the causes of difficult airway intubation are body fluids obscuring the laryngeal view, airway obstruction or edema, obesity, short neck, small mandible, large tongue, facial trauma, or the need for cervical spine immobilization [3]. Among these methods, intubating stylets such as guide-wires result in successful intubation in $78-100 \%$ of difficult airway patients [4,5]. Reported complications from intubating stylets include mild mucosal bleeding and sore throat, but breakage or shearing of the tip of the stylet and subsequent unnoticed airway obstruction is a very rare event being reported in only six to seven cases before.

Use of the endotracheal tube stylet is one of the interventions advised by the American Society of Anesthesiology to manage a difficult airway and include awakeintubation. There are afew reports in theliterature of plastic endotracheal stylet remaining in the tracheobronchial tree [6-8]. There are a few reports of broken metal pieceguide that remained unnoticed inETT, but it was in ETT. In our report, we described migration of the intubation stylet to the distal trachea and left main bronchus that presented on computed tomography image, which was removed by fiberoptic bronchoscopy.

Our patient was brought from another hospital; hence, we could not find out the exact reason behind the incident. We found a similar case reported by Fathi et al. [4] in which about a $4.5 \mathrm{~cm}$ metal piece of stylet used during the last intubation attempt was removed from the patient's tracheobronchial tree.

However, in a previously published similar case [8], the main reason behind the breaking of the stylet was significant overuse, while the intensivist might have failed to notice the leftover stylet, as he/she might have become involved in patient management.

Our patient had a short neck and was obese. She had a history of repeated intubation elsewhere in the past 6 months. In one of those intubations, the intensivist might have used ETT with stylet, which might have accidentally broken and been left over. We could not trace the previous chest radiography to trace the time of the incident. Immediately after removal of the FB, the patient's condition improved, as she started using NIV, which she was refusing earlier. She was discharged to her hometown after 3 days of procedure.

\section{Conclusion}

We would like to conclude that obese patients are always difficult-to-intubate cases. The intensivist has to be careful in negotiating airways, and, if the stylet or 
any other device used to navigate the endotracheal tube should not be left over, as in the present case, it is not only necessary to carry out an assessment of the stylet before intubation, but during the intubation and after that. Not noticing the breakage of the stylet was the reason behind the worsening condition of our patient.

\section{Financial support and sponsorship}

Nil.

\section{Conflicts of interest}

There are no conflicts of interest.

\section{References}

1 Modir H, Moshiri E, Malekianzadeh B, Noori G, Mohammadbeigi A Endotracheal intubation in patients with difficult airway: using laryngeal mask airway with bougie versus video laryngoscopy. Med Gas Res 2017; 7:150-155
2 Driver BE, Prekker EM, Klein RL, Readron FR, Miner RJ, Fagerstrom TE, et al. Effect of use of a bougie vs endotracheal tube and stylet on first-attempt intubation success among patients with difficult airways undergoing emergency intubation: a randomized clinical trial. JAMA 2018; 319:2179-2189

3 Brown CA, Bair AE, Pallin DJ, Walls RM, et al. Techniques, success, and adverse events of emergency department adult intubations. Ann Emerg Med 2015.

4 Fathi M, Farzange B, Mojtabaee M, Nikzamir A. A piece of broken metal from intubation stylet retained in tracheobronchial tree a case report. Tanaffos 2014; 13:51-54.

5 Apfelbaum JL, Hagberg CA, Caplan RA, Blitt CD, Connis RT, Nickinovich $D G$, et al. Practice guidelines for management of the difficult airway: an updated report by the American Society of Anesthesiologists Task Force on Management of the Difficult Airway. Anesthesiology 2013; 118:251-70

6 Boyd RL, Bradfield HA, Burton EM, Carter BS. Fluoroscopyguided retrieval of a sheared endotracheal stylet sheath from the tracheobronchial tree in a premature infant. Pediatr Radiol 1999; 29:575-7.

7 Shetty S, Power S, Afshar K. A sheared stylet. BMJ Case Rep 2010; 2010: bcr0220102725.

8 Sharma A, Jain V, Mitra JK, Prabhakar H. A rare cause of endotracheal tube obstruction: a broken stylet going unnoticed - a case report. Middle East $J$ Anaesthesiol 2008; 19:909-11. 